\title{
Safety Design Strategy for TREAT Transient Test Capability
}

September 2012

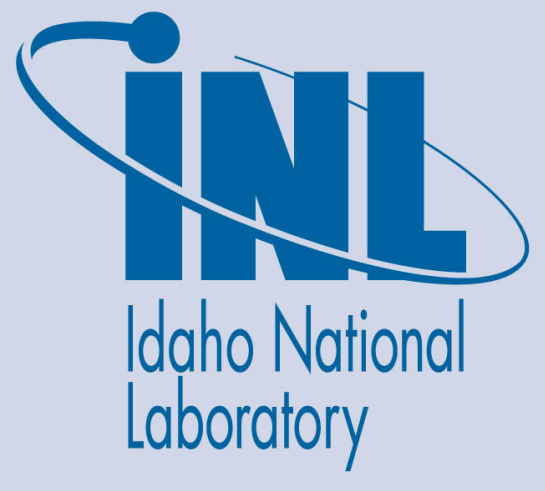

The INL is a U.S. Department of Energy National Laboratory operated by Battelle Energy Alliance 
INL/EXT-12-26455

\title{
Safety Design Strategy for TREAT Transient Test Capability
}

September 2012

\author{
Idaho National Laboratory \\ Idaho Falls, Idaho 83415
}

http://www.inl.gov

Prepared for the

U.S. Department of Energy

Office of Nuclear Energy

Under DOE Idaho Operations Office

Contract DE-AC07-05ID14517 
INL/EXT-12-26455

Revision 0

\section{DISCLAIMER}

This information was prepared as an account of work sponsored by an agency of the U.S. Government. Neither the U.S. Government nor any agency thereof, nor any of their employees, makes any warranty, expressed or implied, or assumes any legal liability or responsibility for the accuracy, completeness, or usefulness, of any information, apparatus, product, or process disclosed, or represents that its use would not infringe privately owned rights. References herein to any specific commercial product, process, or service by trade name, trade mark, manufacturer, or otherwise, does not necessarily constitute or imply its endorsement, recommendation, or favoring by the U.S. Government or any agency thereof. The views and opinions of authors expressed herein do not necessarily state or reflect those of the U.S. Government or any agency thereof. 


\section{BEA Nuclear Safety Engineering \\ Safety Design Strategy for TREAT Transient Test Capability}

INL/EXT-12-26455

Revision 0

September 2012

Developed by:

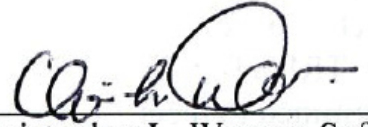

Christopher L. Warner, Safety Analyst,

Nuclear Safety Associates

Reviewed by:

Approval per e-mail to B. Christensen

S.S. Cunningham, TREAT Nuclear Facility Manager

$9 / 27 / 12$

Date

Approved by:

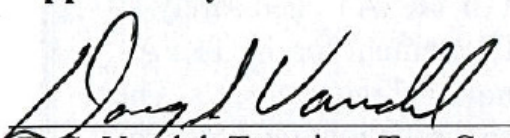

D.S. Vandel, Transient Test Capability Project Manager

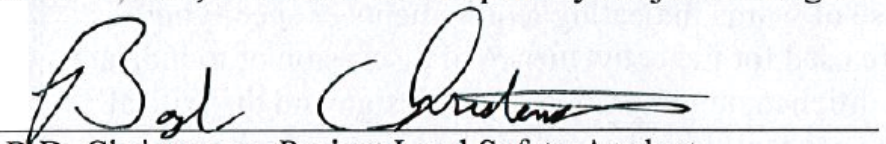

B.D. Christensen, Project Lead Safety Analyst

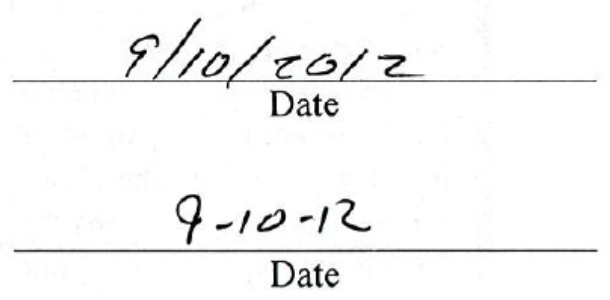

Approval per e-mail to B. Christensen C.L. Pope, MFC Facility Safety Engineering

$9 / 20 / 12$

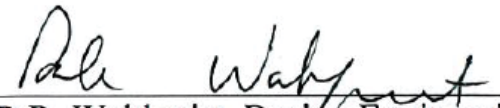

D.R. Wahlquist, Desifon Engineering Manager

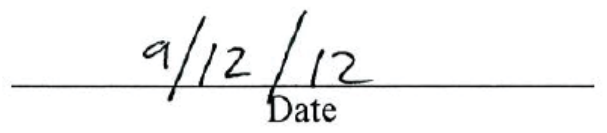

Approval per e-mail to B. Christensen A. Clark, Director of Nuclear Assurance

$9 / 14 / 12$ Date 


\begin{abstract}
In accordance with the requirements of U.S. Department of Energy (DOE) O 413.3B, "Program and Project Management for the Acquisition of Capital Assets," safety must be integrated into the design process for new or major modifications to DOE Hazard Category 1, 2, and 3 nuclear facilities. The intended purpose of this requirement involves the handling of hazardous materials, both radioactive and chemical, in a way that provides adequate protection to the public, workers, and the environment. Requirements provided in DOE O 413.3B and DOE O 420.1B, "Facility Safety," and the expectations of DOE-STD-1189-2008, "Integration of Safety into the Design Process," provide for identification of hazards early in the project and use of an integrated team approach to design safety into the facility. This safety design strategy provides the basic safety-in-design principles and concepts that will be used for the TREAT Transient Test Capability project. While this project does not introduce new hazards to the TREAT, it has the potential for significant effects to safetyrelated systems, structures, and components that are credited in the TREAT safety basis and are being replaced. Thus the project has been determined to meet the definition of a major modification and is being managed accordingly.
\end{abstract}

NOTE:

This document presents the safety design strategy for the restart of TREAT aged safetyrelated equipment and systems. It is based on the Mission Need Statement for the TREAT restart project which documents preliminary functional and operational requirements. These are preliminary, pre-conceptual requirements subject to revisions throughout the prescribed DOE project management process. Use of words indicating requirements or specifying intention, such as "shall" or "will," are used for the convenience of discussion or to indicate requirements or activities that are conditioned on maturation of the design and the critical decision approval corresponding to the concept/design stage for the project. Such usage should not be construed to mean that a final design selection has been made. 


\section{TABLE OF CONTENTS}

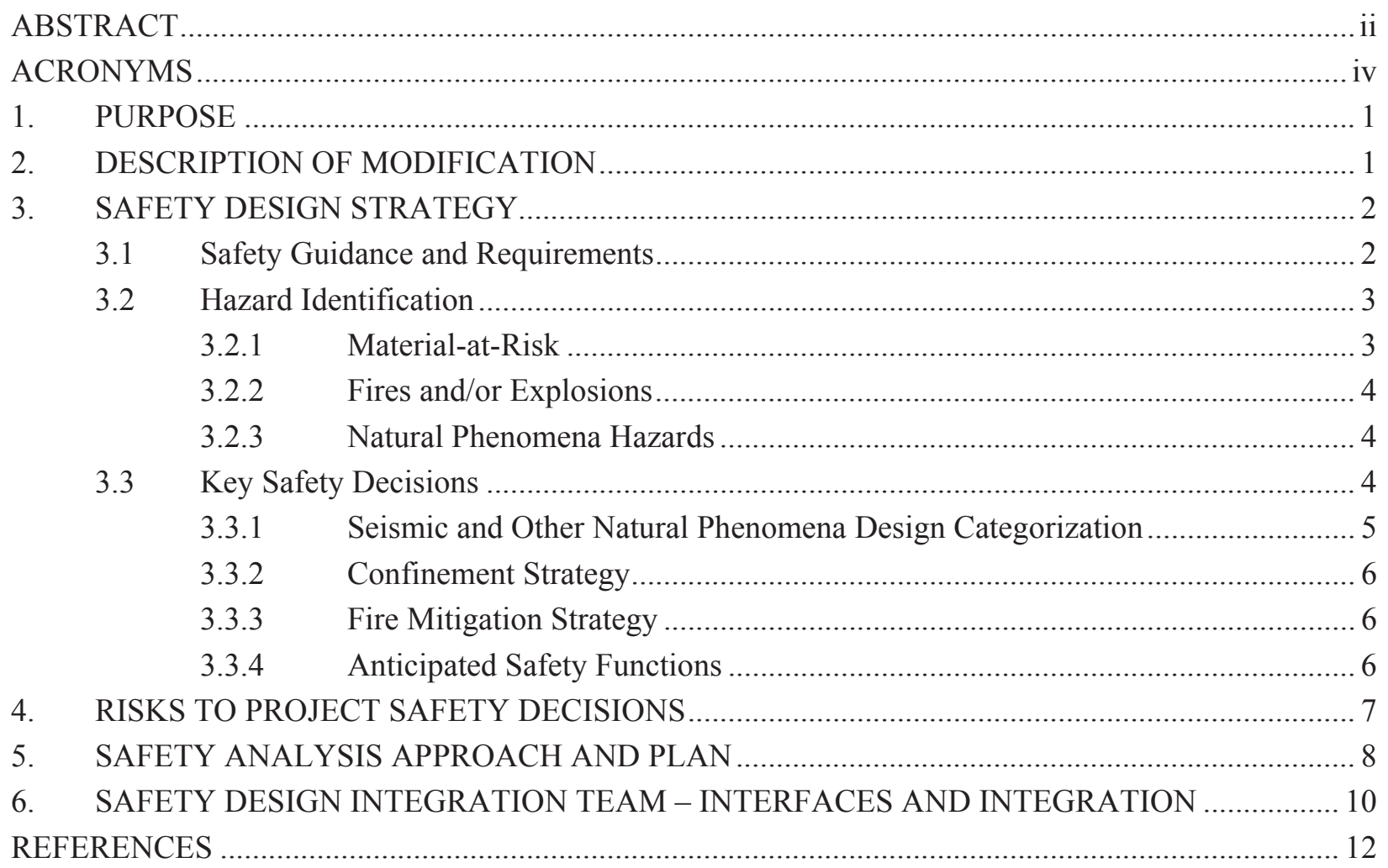

\section{TABLE OF TABLES}

Table 6-1. Safety design integration team. 


\section{ACRONYMS}

\begin{tabular}{|c|c|}
\hline ARCS & automatic reactor control system \\
\hline $\mathrm{BIO}$ & basis for interim operations \\
\hline CRIS & control rod interlock system \\
\hline CSDR & conceptual safety design report \\
\hline DAS & data acquisition system \\
\hline DBA & design basis accident \\
\hline DBT & design basis threat \\
\hline DOE & Department of Energy \\
\hline DSA & documented safety analysis \\
\hline EBR-II & Experimental Breeder Reactor-II \\
\hline ECAR & engineering calculations and analysis report \\
\hline EDMS & Electronic Data Management System \\
\hline FSAR & final safety analysis report \\
\hline $\mathrm{HC}$ & hazard category \\
\hline IBC & International Building Code \\
\hline $\mathrm{I} \& \mathrm{C}$ & instrument and control \\
\hline INL & Idaho National Laboratory \\
\hline IPT & integrated project team \\
\hline LHM & loop handling machine \\
\hline LWR & Light Water Reactor \\
\hline MAR & material-at-risk \\
\hline $\mathrm{MCA}$ & material condition assessment \\
\hline MRCS & manual reactor control system \\
\hline $\mathrm{NE}$ & Office of Nuclear Energy \\
\hline $\mathrm{NPH}$ & natural phenomena hazard \\
\hline $\mathrm{NRC}$ & Nuclear Regulatory Commission \\
\hline $\mathrm{OA}$ & Office of Independent Oversight and Performance Assurance \\
\hline $\mathrm{PC}$ & performance category \\
\hline PDSA & preliminary documented safety analysis \\
\hline PHA & preliminary hazard analysis \\
\hline PPS & plant protection system \\
\hline PSDR & preliminary safety design report \\
\hline $\mathrm{RCS}$ & reactor control system \\
\hline
\end{tabular}


INL/EXT-12-26455

Revision 0

$\begin{array}{ll}\text { RHOCS } & \text { reactivity control system } \\ \text { RTS } & \text { reactor trip system } \\ \text { SAR } & \text { safety analysis report } \\ \text { SC } & \text { safety-class } \\ \text { SDS } & \text { safety design strategy } \\ \text { SPTL } & \text { single pin test loop } \\ \text { SS } & \text { safety-significant } \\ \text { SSC } & \text { structures, systems, and components } \\ \text { SSE } & \text { safe shutdown earthquake } \\ \text { TREAT } & \text { Transient Reactor Test Facility } \\ \text { TRIGA } & \text { training research and isotope reactor } \\ \text { UBC } & \text { Uniform Building Code } \\ \text { UPS } & \text { uninterruptable power supply } \\ \text { VA } & \text { vulnerability assessment }\end{array}$




\section{Safety Design Strategy for TREAT Transient Test Capability}

\section{PURPOSE}

In accordance with Department of Energy (DOE)-STD-1189-2008, "Integration of Safety Into the Design Process," this safety design strategy (SDS) for the Transient Reactor Test Facility (TREAT) Transient Test Capability project at the Idaho National Laboratory (INL) describes the overall safety strategy, describes the strategy for certain high-cost, safety-related design decisions, identifies key assumptions or inputs that may represent potential risks to design decisions, and identifies expected safety deliverables throughout the course of the project. In accordance with the requirements of DOE O 413.3B, "Program and Project Management for the Acquisition of Capital Assets,", safety must be integrated into the design process for new or major modifications to DOE Hazard Category (HC) 1, 2, and 3 nuclear facilities. Safety analysis documentation will meet the requirements of 10 CFR 830, "Nuclear Safety Management," Subpart B, "Safety Basis Requirements."”

\section{DESCRIPTION OF MODIFICATION}

In order to resume transient fuel testing in the United States, and as part of the preferred alternative identified by a team of subject matter experts from several DOE laboratories and documented in "Final Report for the Resumption of Transient Testing of Nuclear Fuels Analysis of Alternatives," "the Transient Test Capability Project proposes to inspect, test, and refurbish TREAT. The facility operated for 35 years conducting high-power transient tests of nuclear fuels and materials. TREAT last operated in 1994 and has been maintained in a standby condition with the driver fuel inside the reactor since that time. TREAT is very accessible for experiments and may be configured accordingly. While TREAT has been maintained in good condition, the existing fuel condition requires characterization; in addition, the data acquisition system (DAS), reactor control system (RCS) electronics, and time-resolved imaging system (hodoscope) are now outdated and are anticipated to be either replaced or updated. Additionally, TREAT may require test loops of differing designs, in-core testing equipment, fission chambers, high-temperature thermo-couples, and optical line-of-sight detectors. ${ }^{5}$

The proposed action would include the following tasks: ${ }^{6}$

- Inspect and characterize the existing reactor driver fuel elements' clad thickness and oxide film

- Refurbish the reactor trip system (RTS), fuel test loop control module, radiation monitoring equipment, cranes, hodoscope (a neutron-based fuel motion detector), transient rod, and control rod hydraulic drive systems, casks, experiment loop control module, and reactor cooling system

- Relocate and replace the RCS with functionally equivalent equipment

- Replace the DAS with functionally equivalent equipment.

The driver fuel's cladding constitutes the primary confinement of the TREAT reactor. Oxidation and metal loss of the cladding determines the useful life of the driver fuel. The feasibility of using the existing TREAT driver fuel needs to be assessed. Fuel and fuel cladding inspection methods will be established, and the feasibility of how to inspect them will be determined. 
The TREAT instrumentation and control (I\&C) systems provide the necessary subsystems to shut down the reactor upon development of abnormal conditions, to control the reactor in order to perform in-reactor experiments, and to continuously monitor the reactor status. The major I\&C systems are made up of the following subsystems:

- Plant protection system:

○ Reactor trip system (RTS).

○ Reactivity control system (RHOCS).

- Reactor control system (RCS):

- Manual reactor control system (MRCS).

- Automatic reactor control system (ARCS).

- Control rod interlock system (CRIS).Data acquisition system (DAS).

The shutdown function is provided by the plant protection system (PPS). The PPS is composed of the RTS that senses the need for and commands a reactor shutdown, and the portion of the RHOCS that implements a shutdown command by rapidly inserting all control rods by means of scram mechanisms associated with each rod. Control of the reactor is provided by the RCS and RHOCS, which position the control rods by means of control rod drives.

The DAS is composed of analog and digital signal collection equipment and related computers and data storage equipment. The DAS collects, stores, and transmits data during all modes of reactor operation. The types of RCS and PPS data collected by the DAS are core fuel temperature, core coolant temperature, transient rod position, linear power, integrated power, log power, reactor period, and scram commands. The I\&C Room 108 in MFC-720 contains the instrumentation required to monitor reactor conditions during all modes of operation and to send the required signals to the TREAT control room (MFC-724) for remote monitoring.

When completed, the Transient Test Capability Project will 1) replace or refurbish obsolete reactor safety-related equipment with a state-of-the-art platform of data acquisition, as well as RCS, experiment support systems, and RTS, 2) inspect and characterize the existing reactor driver fuel elements' clad thickness and oxide film condition for continued safe operation, and 3) refurbish existing supporting equipment for fuel and experiment handling. The reactor control and DAS replacement portion of the project will provide the functionally equivalent replacement, installation, and testing of the systems, including necessary interface development, that ensures safe and reliable plant operations and addresses all functional and operational requirements as credited by the current, approved safety basis. ${ }^{7,8}$

\section{SAFETY DESIGN STRATEGY}

The overall safety strategy for the TREAT Transient Test Capability project is presented in the following sections.

\subsection{Safety Guidance and Requirements}

Pre-conceptual design for the TREAT Transient Test Capability project is substantially based on functionally no-betterment replacement of aged safety-related equipment and/or systems. No-betterment replacement, in itself, does not lead to the conclusion that the project constitutes a major modification per the guidance of DOE-STD-1189. However, due to the obsolescence of the aged equipment designs and the technological advances over more than two decades since the last TREAT modification, the preconceptual design strategy includes system modifications that benefit from improvements in equipment designs and technological advances. The development of this strategy requires careful attention to 
maintaining adherence to applicable and credited engineering and nuclear safety design criteria (e.g., active seismic qualification, redundancy and diversity for safety functions) to ensure no adverse impacts to their designated safety functions. Based on these considerations, it is concluded that this project constitutes a major modification, ${ }^{9}$ and this SDS is tailored accordingly.

Protection of the public, workers, and environment from hazards associated with operation, maintenance, and modification of TREAT is assured through compliance with the existing facility safety basis, which provides the analysis of facility hazards, specifies the controls necessary to prevent and mitigate the hazards, and defines safety management programs which afford a level of safety to the public, workers, and environment. The existing safety basis documents for TREAT include S3942-0001-YT w/ Addendum 2, ${ }^{10}$ Z0003-0005-OS, "TREAT Technical Specifications,"8 and DOE-issued TREAT safety evaluation reports. The safety-in-design approach for this project is through compliance with DOE-STD-1189-2008 and the design commitments as stated in the final safety analysis report (FSAR) addendum ${ }^{10}$ as follows:

The nuclear safety rule includes requirements for the development of a preliminary documented safety analysis (PDSA) for a new Hazard Category 1, 2, or 3 nuclear facility, or a major modification to such a facility. DOE-STD-1189, "Integration of Safety into the Design Process," supports implementation of this requirement. The standard integrates the development of a PDSA as part of the overall design process for new facilities or major modifications to existing facilities.

Upgraded safety basis documents, which include a basis for interim operations $(\mathrm{BIO})^{11}$ and accompanying technical safety requirement (TSR), ${ }^{12}$ have also been prepared and submitted to Department of Energy Idaho Operations Office (DOE-ID) for approval. However, this BIO/TSR covers only current shutdown activities and operations. The introduction of the activities and operations described herein will require additional safety-basis documentation as discussed in Section 5.

The design and safety evaluation will be completed in accordance with 10 CFR 830, Subpart B, Table 2 of Appendix A as modified by GDE-578, "Nuclear Safety Integration Plan for the Restart of the Transient Reactor Test Facility." 13 A tailored approach will be used; focusing on ensuring that replacement safety-related equipment continues to fulfill the credited safety envelope and does not introduce new, adverse failure modes. Existing FSAR analyses will be updated as necessary where system response models are affected by the operational characteristics of the replacement equipment. The nuclear safety integration plan, GDE-578, includes elements of DOE-STD-3009, NUREG-1537, "Guidelines for Preparing and Reviewing Applications for the Licensing of Non-Power Reactors,"14 and American National Standards Institute (ANSI)/American Nuclear Society (ANS)-15.21, "Format and Content for Safety Analysis Reports for Research Reactors." ${ }^{\prime 2}$ See Section 5 and GDE-578 for additional details of the safety analysis approach and plan.

\subsection{Hazard Identification}

\subsubsection{Material-at-Risk}

The TREAT material-at-risk (MAR) consists of the TREAT reactor fuel in the reactor core and stored in storage pits, the Mark-III loops, single pin test loops (SPTLs) and various sealed sources, various isotopic sources stored in the high bay storage areas, Experimental Breeder Reactor-II (EBR-II) elements and loop debris in the north and south high bay storage areas, and capsule and training research and isotope reactor (TRIGA) fuel elements. The TREAT reactor is a Category B reactor with a steadystate operating power level up to $120 \mathrm{KW}$ with transient pulses with initial power periods as short as 
$23 \mathrm{~ms}$, reaching peak powers of up to 16,000 MW, and depositing energies of up to $2900 \mathrm{MJ}$. As such, TREAT has a radioactive material inventory with the potential for public consequences in the rem range (5-25 rem $)^{7}$ under specified accident conditions during transient testing. These scenarios will be reevaluated in the facility safety basis development. As long as the existing fuel is retained for future operations, the proposed project has no effect on the quantity of MAR. If additional/replacement fuel elements are required, evaluation of the impact on MAR will also be required.

\subsubsection{Fires and/or Explosions}

The reactor is shut down, in a standby condition, and the control rod drive mechanisms have been electrically disconnected to prevent operation. The uninterruptable power supply (UPS) units have dead batteries and are obsolete and will need to be upgraded to restart the reactor. ${ }^{16}$ Restarting of associated electrical systems like the diesel generators, UPS, and switchgear include inherent fire/explosion hazards that will be minimized through the proper design and selection of replacement materials as needed. Recharging the UPS batteries introduces the explosion hazard associated with hydrogen generation. Any fire or explosion associated with these components will not introduce any new mechanism for release of radioactive material from TREAT; however, the impact to the safety function for the safety-related components will need to be evaluated to ensure the design is adequate during both restart and operations to preclude adverse impact to the reactor safety.

\subsubsection{Natural Phenomena Hazards}

Natural phenomena hazards (NPHs), including earthquakes (seismic events), extreme wind, tornado, flood, volcanic, and lightning, are potential hazards to the facility for causing building damage and/or failure of safety-related operational equipment. These NPH hazards were evaluated in the TREAT $\mathrm{FSAR}^{7}$ for existing facilities in support of reactor operations. The original TREAT facility design complied with the Uniform Building Code (UBC) in effect at the time of construction. No dynamic seismic analysis of building ability to withstand earthquake loadings has been demonstrated. The original construction and Addition 1 did not apply seismic loading criteria. The design of Addition 2 used the seismic loading criteria for seismic zone 3 of the UBC. The design of the upgraded TREAT construction employed the seismic loading criteria for seismic zone 3 of the UBC with an importance factor of 1.5. A qualitative evaluation of various portions and components of the TREAT reactor building ${ }^{17}$ indicate that the reactor structure, control rod drive support structure, and 60-ton overhead crane are considered to meet Performance Category 2 (PC-2) seismic design criteria in accordance with the DOE-STD-10202002 and International Building Code (IBC) 2000. The following features or components of the TREAT reactor building were evaluated as not meeting PC-2 requirements, warranting further analyses as necessary: 1) the reactor building including the original building, first addition, third addition, fourth addition, and 2) the 15-ton overhead crane.

\subsection{Key Safety Decisions}

Decisions will be made during the initial project life cycle that will affect the eventual design and construction/installation of the structures, systems, and components (SSCs) for the TREAT Transient Test Capability project. Those key safety decisions that could potentially result in significant cost are addressed herein consistent with the hazard categorization for TREAT. TEV-1516, "Materials and Fuels Complex Documented Safety Analysis Extent of Condition Review," 18 Appendix H, cited instances of difficulty in evaluating and comparing the current safety basis, S3942-0001 -YT, "TREAT Final Safety Analysis Report," to the pending upgraded safety basis, SAR/TSR-409, "Basis for Interim Operation for the Transient Reactor Test Facility," due to differences in preparation and radiological guidelines. TEV1516 expressly states that "controls to protect the collocated workers and the public are in place and 
considered adequate;" however, TEV-1516 only addressed current activities within TREAT and was not necessarily developed with consideration of TREAT Transient Test Capability project activities. Thus, if the current safety basis (S3942-0001 -YT) is maintained, then the safety envelope described therein must be reviewed for adequacy with corresponding addenda and/or revision as necessary. Similarly, if the pending safety basis (SAR/TSR-409) is approved and adopted, then the safety envelope described therein must be reviewed for adequacy with corresponding addenda and/or revision as necessary.

SSCs at TREAT are classified in the currently-approved safety-basis into two categories: (1) safety-related and (2) nonsafety-related. The term "safety-related" ${ }^{19}$ refers to those SSCs that are relied upon during or following design-basis events to ensure (a) the integrity of the primary coolant pressure boundary, (b) the capability to shut down the reactor and maintain it in a safe shutdown condition, and (c) the capability to prevent or mitigate the consequences of accidents that result in potential off-site exposures. The selection of SSCs and TSRs for the TREAT transient test capability safety basis will be performed following the safety analysis approach and plan outlined in Section 5 and GDE-578.

\subsubsection{Seismic and Other Natural Phenomena Design Categorization}

Natural phenomena hazard (NPH) categorization is dependent upon the assigned SSC safety category. Safety-related equipment is divided into two classes for the purpose of establishing seismic, wind, and flood performance requirements in accordance with Regulatory Guide $1.70 .^{20}$ These classes are Seismic Category I and Non-Seismic Category I. Those safety-related equipment needed to mitigate the effects of the safe shutdown earthquake (SSE) are designated Seismic Category I in accordance with Regulatory Guide 1.29, "Seismic Design Classification.,"21

An engineering calculations and analysis report (ECAR) was prepared in 2009 to collect known TREAT structural information. ${ }^{22}$ The scope of the ECAR included an exhaustive search INL Electronic Data Management System (EDMS) and old Argonne TREAT project files to locate applicable documents, specifically structural analyses, which pertained to the TREAT Reactor Building or the other specific reactor building components. During the information gathering, the only applicable structural analyses located were for the 60-ton crane, the reactor support structure, and the control rod seismic restraints. Concurrently, information pertaining to wind and seismic requirements was found from reviewing construction drawings and design descriptions. In some cases, neither the drawings nor design descriptions provided sufficient design load information.

The historical information was then used to forensically determine by qualitative evaluation whether or not wind and seismic loading criteria used for the original design of the reactor building and later modifications of building components meets current PC-2 requirements. The only available structural analyses that were found pertained to the 60 -ton crane, the reactor support structure, and the control rod seismic restraints. The results of the qualitative evaluation of various portions and components of the TREAT reactor building indicate the following concerning their capability to meet current PC-2 requirements:

- The following areas/components of the TREAT reactor building appear to meet current PC-2 requirements:

- Reactor structure

- Reactor control rod drive seismic restraints

- Below-grade fuel storage silos/pits

- 60-ton overhead crane

- ATL cask stand. 
- The following areas and components of the TREAT reactor building do not appear to meet current PC-2 requirements, and further analyses are required:

- Reactor building, including original building, first addition, second addition, third addition, fourth addition, and TREAT upgrade addition.

- 15-ton overhead crane.

- Basement auxiliary room.

\subsubsection{Confinement Strategy}

The confinement strategy for TREAT is described in the current safety basis and includes items like, but not limited to, fuel element cladding, cask handling and LHM storage and is potentially affected by the TREAT Transient Test Capability project. Information from inspection and characterization activities of the existing reactor driver fuel elements' clad thickness and oxide film conditions will be considered appropriately in the facility safety basis development.

Defense Nuclear Facilities Safety Board (DNFSB) Recommendation 2004-2 23 recommends that DOE require an active confinement ventilation system for all new and existing Hazard Category 2 defense nuclear facilities with the potential for a radiological release. The Board felt there was inappropriate reliance on passive confinement in some cases. The recommendation further suggests active confinement ventilation systems are classified as safety-class (SC) or safety-significant (SS). In the implementation plan in response to DNFSB Recommendation 2004-2, DOE stated, "DOE agrees that active confinement ventilation systems can provide safety benefit and are normally the preferred alternative when a building confinement strategy is needed to provide adequate protection to the public or collocated workers." 24 The DNFSB recommendation and DOE implementation plan will be considered appropriately in the TREAT facility safety basis development.

\subsubsection{Fire Mitigation Strategy}

The existing safety basis includes a fire hazards analysis, ${ }^{25}$ which will be updated to current standards. The fire mitigation strategy for the TREAT Transient Test Capability project is to provide an appropriate level of fire protection based on code of record and fire hazards analysis. Modifications to existing equipment and structures will not be made for the sole purpose of brining a system up to the current code unless warranted by the fire hazards analysis. The fire protection design will comply with DOE O 420.1B, "Facility Safety,"26 Chapter II Section 3c, and modifications to existing structures (e.g., piping or power penetrations through existing credited fire barriers) will be designed to maintain the existing, credited fire safety design for the SSC being modified or improve the design if required by the fire hazards analysis. Fire safety analysis will be drafted and updated consistent with the maturation and phase of the design, per the requirements of DOE O 420.1B Chapter II.

\subsubsection{Anticipated Safety Functions}

At the current pre-conceptual phase for this project, the evaluation of alternative designs and selection of preferred options may result in the derivation of new or modification of existing safety functions for the SSCs being replaced. However, based on the information available at this pre-conceptual phase, it is anticipated that the replacement SSCs will assume similar safety functions as the existing SSCs. The safety functions will be developed in more detail as the project design progresses.

The current safety basis (S3942-0001 -YT and associated technical specifications) was derived in accordance with DOE O 5480.1 A, ${ }^{27}$ Chapter VI, "Safety of Department of Energy Owned Reactors," dated August 13, 1981, and the Light Water Reactor (LWR) edition of Nuclear Regulatory Commission 
(NRC) Regulatory Guide 1.70, "Standard Format and Content of Safety Analysis Reports for Nuclear Power Plants," Revision 3, dated November $1978 .{ }^{20}$ Comparatively, the pending upgraded safety basis (BIO and TSR) was derived in accordance with 10 CFR 830, Subpart B, and DOE-STD-3011-2002, "Guidance for Preparation of Basis for Interim Operation (BIO) Documents." 28 The safety analysis approach for pending upgraded safety basis was markedly different from that used for the currently approved safety basis. Furthermore, the work activities covered by the current safety basis are very different from the work activities to be covered by the pending upgraded safety basis. Thus, a one-for-one comparison between the two safety bases is problematic. The current safety basis was written from the perspective of reactor functionality with inherent safety and radiation protection interwoven; comparatively, the pending upgraded safety basis includes distinct, separate safety analysis considering the facility and collocated workers, and general public. The current safety basis does not specifically identify SC, or SS SSCs, while the pending upgraded safety basis identifies two SS-SSCs but, as stated, for activities very different from what will be experienced under the scope of this project. The selection of SSCs and TSRs for the TREAT transient test capability safety basis will be performed following the safety analysis approach and plan outlined in Section 5 and GDE-578.

\section{RISKS TO PROJECT SAFETY DECISIONS}

Because the proposed TREAT Transient Test Capability project is substantially based on nobetterment replacement of existing aged and obsolescent original TREAT equipment with functionally equivalent equipment, at face value it does not introduce any new significant hazards requiring new accident analysis. However, neither the current safety basis nor pending upgraded safety basis were written from the perspective of expected work activities and associated hazards specific to the future scope of work being considered as part of this project scope. As such, neither the current safety basis nor pending upgraded safety basis expressly assesses the facility worker against project-specific potential hazards, nor uses a location other than $100 \mathrm{~m}$ for collocated workers, and does not take into account that the equipment is not the same. Furthermore, the existing safety basis does not necessarily conform to the rigors of DOE-STD-3009 or DOE-STD-1189-2008. Thus, an inherent safety analysis risk is the potential introduction of additional controls for protection of the facility worker beyond those identified in either the existing safety basis or the pending upgraded safety basis.

Given the age of the current equipment and the need to replace it to overcome various obsolescence issues, it is appropriate that available technology and commercial experience, as applicable, be incorporated in the design of the replacement system. The incorporation of more recent technology and commercial experience into the design does introduce risks and concerns that the safety function is still fulfilled as effectively as or more effectively than credited in the safety basis. The safety-related designation requires careful attention to maintaining adherence to applicable engineering and nuclear safety design criteria (e.g., seismic qualification, isolation of redundant trains from common fault failures, maintaining appropriate redundancy, and diversity) to ensure no adverse impacts to their designated safety functions. This is the primary risk to project safety decisions and driver for concluding that this project is a major modification per the nuclear safety management rule. ${ }^{9}$

A third risk is purely operational. Because the reactor has not been operated since 1994, some concern exists as to the operability of key components and support equipment. An assumption is that reactor key components and support equipment have been maintained as fully capable; however, this assumption cannot be verified until components or equipment have been fully exercised.

A fourth risk is related to the second risk, which is the operability of the cranes. This is compounded by the 15-ton crane, which currently lacks PC-2 structural analysis. 
A fifth risk is the compatibility of the to-be modified equipment and assets with the TREAT equipment and assets left unmodified. While this risk will continually be mitigated as the various design components mature, it must remain a consideration through the project lifecycle.

A sixth risk is the limited wind and seismic loading design information. This statement in no way contests the conclusions documented in ECAR-1411; quite the contrary, the statement supports the findings. It is specifically stated in ECAR-1411: "It is noted, however, that the only available structural analyses that were found to verify these conclusions are for the 60-ton crane, the reactor support structure, and the control rod seismic restraints." Additional structural analysis is planned to replace the lack of historical structural analyses and to fill the gaps of information which carries with it a level of inherent risk.

Additional risk has been identified for the project with the potential for needed structural modifications as identified in the fire hazard or seismic analyses.

As the project proceeds from the pre-conceptual phase to the conceptual phase and preparation of the CD-1 submittal, the risks to the project safety decision will be identified in more detail and coordinated with the preparation of the Risk Management Plan.

\section{SAFETY ANALYSIS APPROACH AND PLAN}

DOE-STD-1189-2008 provides the guidance for determining if facility modifications constitute a major modification per the definition of 10 CFR 830.3 As stated in the standard, "Where a major modification is found to exist, an SDS must be developed that addresses (1) the need for a conceptual safety design report (CSDR) or preliminary safety design report (PSDR), as well as the required preliminary documented safety analysis (PDSA) to support project phases, (2) the graded content of the PDSA necessary to support the design and modification, (3) the application of nuclear safety design criteria, and (4) the interface with the existing facility, its operations, and construction activities." As noted in Section 3.3.1 above, the primary driver for the conclusion that this project constitutes a major modification is to ensure throughout the design process that the replacement safety-related SSCs, while being updated with current technology and experience, continue to fulfill the safety functions as effectively as or more effectively than credited in the safety basis. This is the primary focus of the safety analysis approach and documentation to be developed for this project. It should be noted that, because the modifications involve no new construction and because the nature of the modifications are a nobetterment replacement, a CSDR and PSDR are unnecessary. This conclusion is supported by preliminary project analysis, and will be refined as appropriate as the project progresses.

The main effort will be to convert the current safety basis (FSAR and technical specifications) and pending upgraded safety basis (BIO and TSR) into a consolidated safety basis utilizing a safe harbor methodology as described in GDE-578. The current safety basis incorporates the evaluation guidelines given in 10 CFR 100, "Reactor Site Criteria," ${ }^{29}$ which have historically been considered acceptable guidelines for DOE test reactors. DOE-ID has provided supplemental information ${ }^{30}$ to the INL on meeting the requirements of 10 CFR 830, Subpart B, including evaluation guidelines for all INL nuclear facility DSA/TSR documents, with the exception of Category A nuclear reactor (i.e., Advanced Test Reactor) DSA/TSR documents. These evaluation guidelines include risk evaluation guidelines and criteria for the selection of SSCs and TSRs. The evaluation guidelines are used for comparison to the consequences of accident sequences analyzed in the safety basis documents and are a qualitative method for determining the application of TSR-level controls to prevent or mitigate the consequences and for designating safety SSCs. The TREAT transient test capability safety basis documents will comply with the supplemental guidance provided by DOE-ID. 
The upgraded TREAT safety basis will address the 10 CFR 830, Subpart B, compliance issues discussed in NS-18308, "MFC Work Plan for Safety Basis Upgrade." ${ }^{31}$ Reviews, new programs, or activities will also be addressed during the upgrade of the safety basis as appropriate. Note, however, that the pending updated safety basis (SAR/TSR-409) that was developed as required by NS-18308 was based on the interim mission for the TREAT facility remaining as a nuclear material storage facility and radioactive material training area. Compliance issues identified in NS-18308 that are still appropriate to the TREAT transient test capability project will be evaluated and addressed as necessary in the upgraded TREAT safety basis.

The safe harbor methodology documented in GDE-578 is similar to the methodology documented and approved for use in GDE-7004, "Final Safety Analysis Report Upgrade Guide for Advanced Test Reactor Critical Facility,"32 and GDE-470, "Documented Safety Analysis (DSA) Conversion Guide for the Neutron Radiography Reactor Facility (NRAD)." 33 However, upon review of the regulatory documents specified in 10 CFR 830, Subpart B, it was determined that NRC Regulatory Guide 1.70 applied to large, commercial reactors and was not applicable for a research reactor, such as TREAT. Further, the ANSI standard for small research reactors did not fully cover the programmatic areas typically described in DOE SARs. Therefore, GDE-578 provides a comprehensive format for the TREAT DSA:

The results of [the GDE-578] analysis... show that a more comprehensive evaluation of both facility safety and operations programmatic integration is presented by the proposed upgraded TREAT SAR format and content. In this manner, the DSA will appropriately describe the complexities and hazards associated with reactor operations. The functional areas described in ANSI/ANS-15.21 are addressed in the proposed TREAT format and content outline, with the exception of the funding, and all of the functional areas described in NRC Regulatory Guide 1.70 are addressed with the exception of siting criteria. The proposed outline also includes the programmatic elements of DOE-STD3009. SAR-400, "INL Standardized Safety Analysis Report," 34 supplemented with facility-specific information, will be used to address the programmatic elements as identified in DOE-STD-3009 in accordance with NS-18308.

Consistent with the guidance stated above, and GDE-578, the following requisite nuclear safety documentation will be either revised or developed as part of the project:

- SDS revisions, as required as design matures

- Preliminary DSA, including a preliminary hazard assessment (PHA)

- Final DSA conforming to the specifications of GDE-578, including a hazard analysis

- TSRs

- Fuel examinations and inspection

This nuclear safety basis documentation will be either developed or revised as described in GDE-578, narrowly tailoring the effort to the above listed documents as necessary to address the major modifications to TREAT. As the project design matures, development of other necessary safety documents and analyses will be required. These supporting documents will include the following as appropriate:

- Quality assurance

- Procedures management

- Maintenance management

- Personnel training

- Conduct of operations 
INL/EXT-12-26455

Revision 0

- Emergency preparedness

- Fire protection

- Waste management

- Radiation protection

- Criticality safety.

\section{SAFETY DESIGN INTEGRATION TEAM - INTERFACES AND INTEGRATION}

The purpose of the project integrated project team (IPT) is to provide cross-functional groups of individuals organized for the specific purpose of delivering a project where the technical, management, budgetary, safety, and security interests are met. Use of IPTs is the primary tool for breaking down the walls that can exist between different organizations, different professions, and different levels within the command structure. A successful IPT brings the diverse elements together to form a unit that is willing to share information and balance priorities and ideologies in efforts to successfully execute the project mission while achieving the overall safety strategy.

The safety design integration team includes appropriate representatives from traditional worker safety disciplines, emergency management, and safeguards and security. The safety IPTs that will be used for this project include the Federal IPT, the contractor IPT, and the local project safety design integration team. Each of these IPTs consists of individuals representing diverse disciplines with specific areas of expertise and the ability to support the Federal Project Director in successful execution of the project. Membership may be full time or part time and will change as the project matures through the various phases from initiation through closeout. Membership will include federal and contractor employees and will consist of the members, or designees, the functional positions of which will be defined between CD-0 and CD-1 and the members identified. The organization and responsibilities of the IPTs are shown in Table 6-1.

The responsibilities of the IPTs include the following:

- Support the Federal Project Director

- Support preparation and submittal of funding request documents, as necessary, to secure project funding

- Support development of the project acquisition strategy

- Ensure interfaces are identified, defined, and managed to completion

- Identify, define, and manage implementation of environment, safety, health, and quality requirements

- Identify and define appropriate and adequate technical scope, schedule, and cost parameters

- Perform periodic reviews and assessments of project performance and status against established performance parameters, baselines, milestones, and deliverables

- Plan and participate in project reviews, audits, and appraisals, as necessary

- Review and comment on project deliverables, as appropriate

- Review change requests and support change control board actions, as appropriate

- Participate in readiness reviews or readiness assessments

- Support preparation, review, and approval of project completion and closeout documentation

- Ensure that safety is fully integrated into design, construction, and operations of the HC-1 nuclear facility. 
INL/EXT-12-26455

Revision 0

Table 6-1. Safety design integration team.

\begin{tabular}{|l|l|}
\hline \multicolumn{1}{|c|}{ Organization } & \multicolumn{1}{|c|}{ Responsibility } \\
\hline \multirow{4}{*}{ DOE } & Acquisition Executive, DOE-NE-2 \\
\cline { 2 - 2 } & DOE NE-3 \\
\cline { 2 - 2 } & Manager, DOE-ID \\
\cline { 2 - 2 } & Deputy Manager - Nuclear Energy, DOE-ID \\
\cline { 2 - 2 } & Assistant Manager of Infrastructure, DOE-ID \\
\cline { 2 - 2 } & Federal Project Director, DOE-ID \\
\hline \multirow{5}{*}{ Transient Test Capability Project } & Project Manager \\
\cline { 2 - 2 } & Project Engineer \\
\cline { 2 - 2 } & Environmental Compliance \\
\cline { 2 - 2 } & Nuclear Safety Engineering \\
\cline { 2 - 2 } & Occupational Safety and Health \\
\hline \multirow{5}{*}{ Support Staff } & Procurement \\
\cline { 2 - 2 } & Planning and Financial Controls \\
\cline { 2 - 2 } & Quality Assurance \\
\cline { 2 - 2 } & Environment, Safety, and Health \\
\cline { 2 - 2 } & Nuclear Operations \\
\hline
\end{tabular}


INL/EXT-12-26455

Revision 0

\section{REFERENCES}

1. DOE-STD-1189-2008, "Integration of Safety into the Design Process," U.S. Department of Energy, 2008.

2. DOE O 413.3B, "Program and Project Management for the Acquisition of Capital Assets," U.S. Department of Energy, November 2010.

3. 10 CFR 830, "Nuclear Safety Management," Subpart B, "Safety Basis Requirements," Code of Federal Regulations, Office of Federal Register.

4. INL/EXT-12-26840, "Final Report for the Resumption of Transient Testing of Nuclear Fuels Analysis of Alternatives", August 2012.

5. INL/EXT-09-16392, "Future Transient Testing of Advanced Fuels,” September 2009.

6. IS-MFC-II-003, "Environmental Assessment Determination for the Resumption of Transient Fuel Testing," September 2011.

7. S3942-0001-YT, “Transient Reactor Test Facility (TREAT) Final Safety Analysis Report”, current revision.

8. Z0003-0005-OS, "Technical Specifications for the Transient Reactor Test Facility (TREAT)", current revision.

9. INL/EXT-12-26062, "10 CFR 830 Major Modification Determination for TREAT Transient Test Capability," Rev. 0, July 2011.

10. S3942-0001-YT-ADD-2, "NS-18308 as an Evaluation of the Safety of the Situation and Justification for Continued Operations of Materials and Fuels Complex Nuclear Facilities," Rev. 3, November 2011.

11. SAR-409, "Basis for Interim Operation for the Transient Reactor Test Facility," Rev 0, DRAFT.

12. TSR-409, "Technical Safety Requirements for the Transient Reactor Test Facility," Rev. 0, DRAFT.

13. GDE-578, "Nuclear Safety Integration Plan for the Restart of the Transient Reactor Test Facility," Rev. 0, April 2012.

14. NUREG-1537, "Guidelines for Preparing and Reviewing Applications for the Licensing of NonPower Reactors”, 1996.

15. ANSI/ANS-15.21, "Format and Content for Safety Analysis Reports for Research Reactors," American Nuclear Society, 1996.

16. TREAT-OI-1018, "Fire Hazards Analysis,” Rev. 1, April 2006.

17. ECAR-1411, "Performance Category 2 Evaluation of the TREAT Reactor Building (MFC-720)," Rev. 0, March 2011. 
18. TEV-1516, "Materials and Fuels Complex Documented Safety Analysis Extent of Condition Review,” Rev 0, April 2012.

19. House, R. K., "Bases for Designation of Safety-Related Equipment in the ATR," PG-T-92-114, EG\&G Idaho, Inc., July 1992.

20. Nuclear Regulatory Guide 1.70, "Standard Format and Content of Safety Analysis Reports for Nuclear Power Plants," Rev. 3, U.S. Nuclear Regulatory Commission, Washington, D.C., November 1978.

21. Nuclear Regulatory Guide 1.29, "Seismic Design Classification,” U.S. Nuclear Regulatory Commission, Washington, D.C., September 1978.

22. ECAR-1411, "Performance Category 2 Evaluation of the TREAT Reactor Building (MFC-720)," Rev. 0, March 2011.

23. John T. Conway letter to Spencer Abraham, "Defense Nuclear Facilities Safety Board Recommendation 2004-2 to the Secretary of Energy," including enclosure DNFSB/TECH-34, Confinement of Radioactive Materials at Defense Nuclear Facilities, December 7, 2004.

24. Samuel W. Bodman letter to A. J. Eggenberger, "Revised Department of Energy (DOE) Implementation Plan (IP) in Response to the Defense Nuclear Facilities Safety Board Recommendation 2004-2, Active Confinement Systems," July 12, 2006.

25. TREAT-OI-1018, “Fire Hazards Analysis,” Rev. 1, April 2006.

26. DOE O 420.1B, “Facility Safety,” U.S. Department of Energy, December 2005.

27. DOE O 5480.1A, "Environmental Protection, Safety, and Health Protection Program for DOE Operations," U.S. Department of Energy, August 13, 1981.

28. DOE-STD-3011-02, "Guidance for Preparation of Basis for Interim Operations (BIO) Documents," U.S. Department of Energy, December 2002.

29. 10 CFR 100, "Reactor Site Criteria," Code of Federal Regulations, Office of the Federal Register, January 2007.

30. M. L. Adams (DOE-ID Contracting Officer) letter to L. A. Sehlke, "Nuclear Safety Rule Supplemental Information,” OS-QSD-05-121, CCN 202983, October 11, 2005.

31. NS-18308, “MFC Work Plan for Safety Basis Upgrade,” Rev. 5, November 2011.

32. GDE-7004, "Final Safety Analysis Report Upgrade Guide for Advanced Test Reactor Critical Facility," Rev. 0, May 2001.

33. GDE-470, "Documented Safety Analysis (DSA) Conversion Guide For The Neutron Radiography Reactor Facility (NRAD),” Rev. 0, January 2008.

34. SAR-400, "INL Standardized Safety Analysis Report," current revision. 